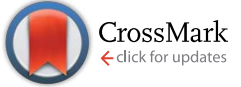

Cite this: Chem. Sci., 2017, 8, 2610

Received 18th November 2016 Accepted 23rd December 2016

DOI: $10.1039 / c 6 s c 05093 j$

www.rsc.org/chemicalscience

\section{Dual gold and photoredox catalysis: visible light-mediated intermolecular atom transfer thiosulfonylation of alkenes $\uparrow$}

\author{
Haoyu Li, ${ }^{a}$ Cuicui Shan, ${ }^{a}$ Chen-Ho Tung ${ }^{a}$ and Zhenghu $\mathrm{Xu}^{\mathrm{ab}}$ \\ Regioselective difunctionalization of alkenes has attracted significant attention from synthetic chemists and \\ has the advantage of introducing diverse functional groups into vicinal carbons of common alkene \\ moieties in a single operation. Herein, we report an unprecedented intermolecular atom transfer \\ thiosulfonylation reaction of alkenes by combining gold catalysis and visible-light photoredox catalysis. A \\ trifluoromethylthio group $\left(\mathrm{SCF}_{3}\right)$ and other functionalized thio groups together with a sulfonyl group were \\ regioselectively introduced into alkenes in the most atom economical manner. A detailed mechanism study \\ indicated that a synergistic combination of gold catalysis and photoredox catalysis is crucial for this reaction.
}

\section{Introduction}

Regioselective difunctionalization of alkenes has the advantage of introducing diverse functional groups into vicinal carbons of common alkene moieties in a single operation and has attracted extensive attention from synthetic chemists. ${ }^{1}$ Of the many catalytic processes that have been developed, a majority requires stoichiometric amounts of an external strong oxidant, such as $\mathrm{PhI}(\mathrm{OAc})_{2}$, Selectfluor (eqn (1)), ${ }^{2}$ and are typically initiated by a transition metal-catalyzed intramolecular addition. Intermolecular difunctionalization of alkenes is more challenging because of the regiochemical issue (eqn (2)). Recently, Stephenson developed an elegant visible light-mediated atom transfer radical addition reaction converting haloalkanes and $\alpha$-halocarbonyl compounds into alkenes. ${ }^{3}$ These neutral redox reactions are very attractive because they are atom-economical and require no additional oxidants.

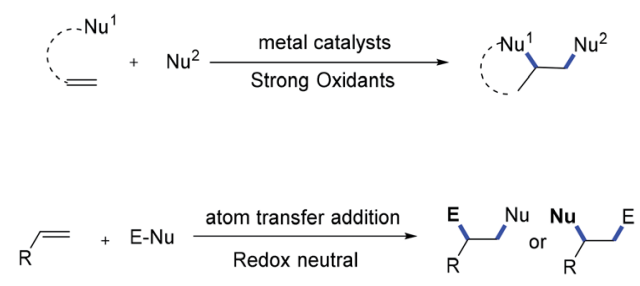

${ }^{a}$ Key Lab for Colloid and Interface Chemistry of Education Ministry, School of Chemistry and Chemical Engineering, Shandong University, Jinan 250100, People's Republic of China. E-mail: xuzh@sdu.edu.cn

${ }^{b}$ State Key Laboratory of Organometallic Chemistry, Shanghai Institute of Organic Chemistry, Chinese Academy of Sciences, Shanghai 200032, PR China

$\dagger$ Electronic supplementary information (ESI) available. CCDC 1494115 for $3 \mathbf{n}$ and 1494114 for 3s. For ESI and crystallographic data in CIF or other electronic format see DOI: $10.1039 / \mathrm{c} 6 \mathrm{sc} 05093 \mathrm{j}$
The trifluoromethylthio $\left(\mathrm{SCF}_{3}\right)$ group is a key structural unit in many pharmaceutical and agrochemical products such as tiflorex, toltrazuril, and vaniliprole. ${ }^{4}$ It is well known that $\mathrm{SCF}_{3}$ groups in a molecule induce even higher lipophilicity than trifluoromethyl substituents, and consequently, the incorporation of $\mathrm{SCF}_{3}$ group into pharmaceuticals could greatly improve their ability to cross lipid membranes. ${ }^{5}$ Because of this, the introduction of a $\mathrm{SCF}_{3}$ group into small molecules has attracted significant attention in synthetic chemistry. ${ }^{6,7}$ Current methods for the construction of $\mathrm{C}-\mathrm{SCF}_{3}$ bonds involve electrophilic trifluoromethylthio reagents ${ }^{6}$ or the nucleophilic $\mathrm{AgSCF}_{3}$ reagent. $^{7}$ Sulfonyl groups are similar to carboxyl or phosphate groups in terms of molecular size and charge distribution, and the sulfonyl group has been introduced into bioactive molecules to improve their activity. ${ }^{8}$ A sulfonyl group has two receptors for hydrogen bonds and this can enhance the binding affinities of drug molecules with target proteins. Sulfones can be easily transformed into other functional groups, such as alkenes, via Julia olefination. ${ }^{9}$ We investigated that whether both $\mathrm{SCF}_{3}$ and sulfonyl groups could be simultaneously introduced into organic compounds in a single step. Moreover, this transformation has not been described to date. This report describes a dual gold and photoredox catalytic approach to the intermolecular atom transfer thiosulfonylation of alkenes.

A combination of visible light-mediated photoredox catal$\mathrm{ysis}^{\mathbf{1 0}}$ and transition-metal-catalysis is possible to bring two distinctive catalytic systems together and achieve unprecedented new reactions..$^{\mathbf{1 1}}$ Recently, the use of gold(I) complexes in photoredox catalysis has gained considerable attention. ${ }^{12,13}$ This photoredox catalytic cycle triggers the conversion of $\mathrm{Au}(\mathrm{I})$ into $\mathrm{Au}(\mathrm{III})$ under mild conditions, a conversion which previously had only been achieved with stoichiometric quantities of strong oxidants. ${ }^{14}$ In 2013, Glorius reported a first dual gold and photoredox-catalyzed reaction, which achieved intramolecular 
oxy- and amino-arylation of alkenes with aryldiazonium salts (Scheme 1A). ${ }^{12 b}$ Toste $e t$ al. took advantage of the visible lightmediated $\mathrm{Au}(\mathrm{I}) / \mathrm{Au}(\mathrm{III})$ cycle to produce arylative ring expansion reactions and carbon-phosphorus cross-coupling reactions (Scheme 1B). ${ }^{12 d, e}$ This visible light-mediated single electron oxidative reaction has been utilized to access gold(III) complexes from gold(I) species. ${ }^{12 k}$ Recently, Hashmi reported an aryldiazonium salts mediated $\mathrm{Au}(\mathrm{I})$ to $\mathrm{Au}(\mathrm{III})$ transformation upon irradiation with blue LED in the absence of a photosensitizer. ${ }^{12 q}$ In all these reactions ${ }^{12}$ the same aryldiazonium salts were used. The development of new gold/photoredox catalysis mode is highly desirable. To achieve the proposed trifluoromethyl-thiosulfonylation reaction in the most atom-economical manner, a difunctionalization reagent, such as $\mathrm{PhSO}_{2} \mathrm{SCF}_{3}$ (2a), is required. This reagent can be easily prepared from $\mathrm{PhSO}_{2} \mathrm{Na}$ and $\mathrm{AgSCF}_{3}$ (for details, see the $\mathrm{ESI} \dagger$ ). We envisioned that the reaction of $\mathrm{PhSO}_{2} \mathrm{SCF}_{3}$ with a cationic gold catalyst in the presence of a photocatalyst would generate an $\mathrm{LAuSCF}_{3}$ species and a benzenesulfonyl radical, which can then add to the alkene forming a new alkyl radical. ${ }^{3 a}$ This radical may oxidize $\mathrm{LAuSCF}_{3}$ into a $\mathrm{Au}$ (II) intermediate, which is further oxidized to a $\mathrm{Au}$ (III) derivative by the $\mathrm{Ru}^{\mathrm{III}}$ catalyst. Subsequent reductive elimination forms the target difunctionalized product, regenerating the $\mathrm{Au}(\mathrm{I})$ catalyst (Scheme 1C). This reaction provided a new approach to introduce trifluoromethylthio $\left(\mathrm{SCF}_{3}\right)$ group at the $\alpha$ position of styrenes.

\section{Results and discussion}

To validate this concept, styrene (1a) and $\mathrm{PhSO}_{2} \mathrm{SCF}_{3}$ (2a) were selected as model substrates to test the feasibility of this hypothesis. After a detailed optimization of reaction conditions, the proposed alkene trifluoromethylthio-sulfonylation product (3a) was achieved in $94 \%$ yield under the standard conditions: a mixture of IPrAuCl (10 mol\%), $\mathrm{AgSbF}_{6}(15 \mathrm{~mol} \%), \mathrm{Ru}(\mathrm{bpy})_{3} \mathrm{Cl}_{2}$ (2.5 mol\%) in DCE (1 mL) was stirred under irradiation for 1-3 h with $100 \mathrm{~W}$ blue LED in a $\mathrm{N}_{2}$ atmosphere (Table 1 , entry 1 ). The

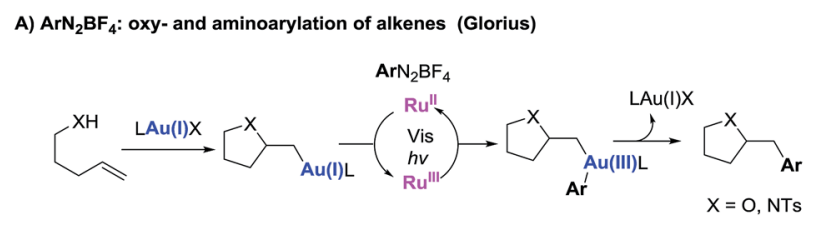

B) $\mathrm{ArN}_{2} \mathrm{BF}_{4}$ : arylative ring expansion and $\mathrm{C}$-P cross-coupling reactions (Toste)

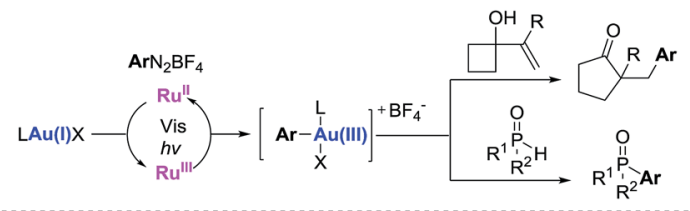

C) $\mathrm{PhSO}_{2} \mathrm{SCF}_{3}$ :thiosulfonylation of alkenes (this work)

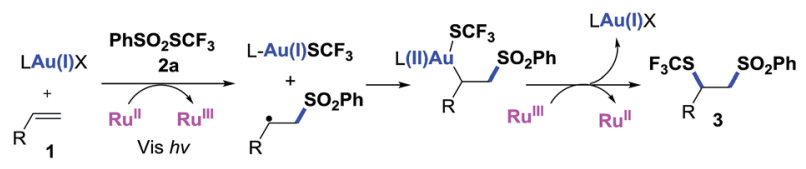

Scheme 1 Dual gold and photoredox catalytic reactions. dual catalytic nature of this reaction was investigated by control experiments, which confirmed that the gold catalyst, the $\mathrm{Ru}(\mathrm{II})$ photosensitizer, and visible light irradiation are all necessary for the reaction (Table S2, $\dagger$ entries 2-5). In the absence of silver salt, the reaction led to a dramatic decrease in the yields (NMR yields $<5 \%$ ), showing that the formation of a cationic gold species is highly important (Table S2, $\dagger$ entry 4). Other gold catalysts, such as $\mathrm{AuCl}, \mathrm{Ph}_{3} \mathrm{PAuCl}$, and Gagosz catalyst $\left(\mathrm{Ph}_{3} \mathrm{PAuNTf}_{2}\right)$, are all less effective than IPrAuCl (entries 2-5). A silver free system using $\operatorname{IPrAuSbF}_{6}$ and $\mathrm{Ru}(\mathrm{bpy})_{3}(\mathrm{PF} 6)_{2}$ led to a slightly lower yield (88\%, entry 6); thus, silver is not necessary in this reaction. Reactions in other solvents, such as acetonitrile and methanol, led to only traces of products and no solvent addition products, indicating that a carbocation mechanism is not involved (entries 7 and 8). Other iridium photocatalysts including, $\operatorname{Ir}\left[\mathrm{dF}\left(\mathrm{CF}_{3}\right) \mathrm{ppy}\right]_{2}(\mathrm{dtbbpy}) \mathrm{PF}_{6}$ and $f a c-\operatorname{Ir}(\mathrm{ppy})_{3}$, were also tested and no product was observed in the reaction system (entries 10-11). The attempt to lower the catalysts loading also led to a lower reaction yield (entry 12).

With these optimized conditions established, the scope of the dual gold and visible light-mediated alkene difunctionalization reaction was explored. As summarized in Table 2, a wide range of styrene-type alkenes were applicable and moderate to good isolated yields of the product were achieved (3a-31). Substrates bearing different electron-withdrawing or electrondonating groups at different positions in the aromatic ring were all compatible with this reaction. A series of functional groups, such as ester, cyano, trifluoromethyl, and halogen, were all welltolerated under the reaction conditions. In particular, the alkene $\mathbf{1 m}$, containing an alkyne moiety, was also applicable to this reaction, giving the corresponding alkene difunctionalized product $(\mathbf{3 m})$ in moderate yield. Note that dienes, such as isoprene, were also amenable to this transformation, generating the 1,4-addition product ( $3 \mathbf{n}$ ) as the major product in $55 \%$ yield, and its structure was confirmed by single crystal X-ray analysis.

Internal alkenes, including acyclic and cyclic alkenes, were also suitable substrates. Most of the reactions exhibited excellent diastereoselectivities. Interestingly, trans-alkenes and cisalkenes afforded the same major products (4o) in similar yields with similar diastereoselectivities, which is a very important feature and also an advantage of this reaction. The relative configuration of the seven-membered product 3 s was unambiguously characterized by single X-ray crystallography. However, the reactions of aliphatic alkenes were unsuccessful under the same conditions.

Organosulfur compounds are ubiquitous in the pharmaceutical industry, materials science, and food chemistry. ${ }^{15}$ The construction of $\mathrm{C}-\mathrm{S}$ bonds is important but challenging ${ }^{16}$ because a sulfur atom could coordinate with a metal catalyst, such as Au, leading to catalyst inactivation. When we applied the abovementioned dual catalysis system to the general thiosulfonylation reaction of alkenes using $\mathrm{PhSO}_{2} \mathrm{SC}_{4} \mathrm{H}_{9}(-1.64 \mathrm{~V}$, vs. SCE) as the reagent, which might be more challenging because of its lower oxidative potential compared to that of $\mathrm{PhSO}_{2} \mathrm{SCF}_{3}(-1.11 \mathrm{~V}$, vs. SCE, Fig. S5, ESI $\dagger)$, to our delight, the reactions were very successful (Table 3). Various alkenes, 
Table 1 Optimization of the reaction conditions ${ }^{a}$

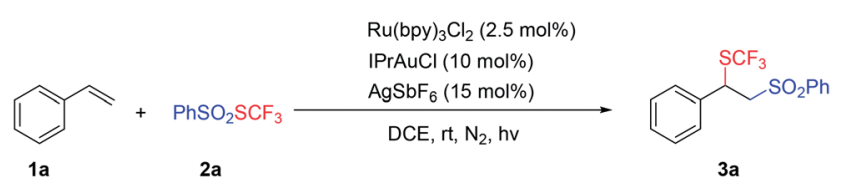

\begin{tabular}{|c|c|c|}
\hline Entry & Variation from the "standard" conditions & Yield $^{b}(\%)$ \\
\hline 1 & None & $94(87)$ \\
\hline 2 & $\mathrm{AuCl}$ instead of IPrAuCl & 0 \\
\hline 4 & IMesAuCl instead of IPrAuCl & 72 \\
\hline 5 & $\mathrm{PPh}_{3} \mathrm{AuNTf}_{2}$ instead of IPrAuCl and $\mathrm{AgSbF}_{6}$ & 67 \\
\hline $6^{c}$ & $\mathrm{IPrAuSbF}_{6}$ instead of IPrAuCl and $\mathrm{AgSbF}_{6}$ & 88 \\
\hline 9 & $\mathrm{Ru}(\text { phen })_{3} \mathrm{Cl}_{2}$ instead of $\mathrm{Ru}(\mathrm{bpy})_{3} \mathrm{Cl}_{2}$ & 67 \\
\hline 10 & $\operatorname{Ir}\left[\mathrm{dF}\left(\mathrm{CF}_{3}\right) \mathrm{ppy}\right]_{2}(\mathrm{dtbbpy}) \mathrm{PF}_{6}$ & 0 \\
\hline 11 & $f a c-\operatorname{Ir}(\mathrm{ppy})_{3}$ instead of $\mathrm{Ru}(\mathrm{bpy})_{3} \mathrm{Cl}_{2}$ & 0 \\
\hline 12 & IPrAuCl (5 mol\%), $\mathrm{AgSbF}_{6}(7.5 \mathrm{~mol} \%), \mathrm{Ru}(\mathrm{bpy})_{3} \mathrm{Cl}_{2}(1.2 \mathrm{~mol} \%)$ & 64 \\
\hline
\end{tabular}

${ }^{a}$ Reaction conditions: a mixture of $\left.1 \mathrm{a}(0.4 \mathrm{mmol}), \mathbf{2 a}(0.2 \mathrm{mmol}), \operatorname{IPrAuCl}(10 \mathrm{~mol} \%), \mathrm{AgSbF}_{6}(15 \mathrm{~mol} \%), \mathrm{Ru}(\mathrm{bpy})\right)_{3} \mathrm{Cl}_{2}(2.5 \mathrm{~mol} \%)$, in DCE $(1 \mathrm{~mL})$ was stirred at rt under irradiation with a $100 \mathrm{~W}$ blue LED at $\mathrm{N}_{2}$ atmosphere. ${ }^{b}$ Determined by ${ }^{19} \mathrm{~F}$ NMR using (trifluoromethyl)benzene as the internal standard. The number in parentheses is the isolated yield. $\operatorname{IPr}=1,3$-bis(2,6-diisopropyl-phenyl)imidazol-2-ylidene, ppy $=2$-phenylpyridine. ${ }^{c} \mathrm{Ru}(\mathrm{bpy})_{3}\left(\mathrm{PF}_{6}\right)_{2}$ instead of $\mathrm{Ru}(\mathrm{bpy})_{3} \mathrm{Cl}_{2}$.

Table 2 Substrate scope of alkene trifluoromethylthiosulfonylation reactions $^{a}$

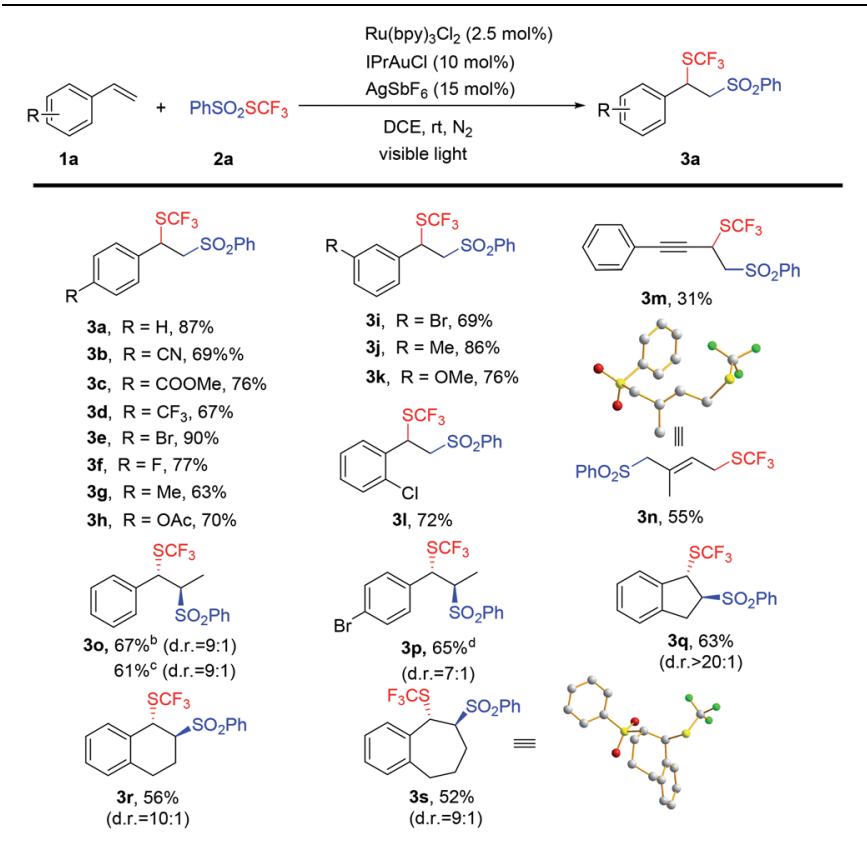

${ }^{a}$ Standard conditions were employed. Isolated yields were reported. Diastereoselectivities were determined by GC-mass. ${ }^{b}$ From $(E)$-alkene.

${ }^{c}$ From $(Z)$-alkene. ${ }^{d}$ From $(Z)$-alkene : $(E)$-alkene $=7: 3$.

including styrenes, internal alkenes, and dienes, were all compatible with this thiosulfonylation reaction, giving the corresponding products in good yields (4a-4r). A large variety of alkyl and aromatic thio groups can be easily introduced into a styrene molecule, generating difunctional products generally in very good yields $(\mathbf{5 a}-\mathbf{5 h})$.

The sulfonyl group $\left(-\mathrm{SO}_{2}-\right)$ is a useful synthon for further transformations. For example, the reaction of compound $4 \mathbf{a}$ with TMSCN or allylsilane in the presence of aluminium chloride provided the sulfur migration substitution products 6 and 7 in good yields (eqn (3) and (4)). This reaction might occur via a neighboring group participating in an $\mathrm{S}_{\mathrm{N}} 1$ type of reaction.

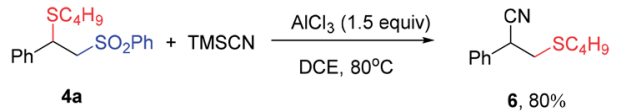

$$
\begin{aligned}
& \underset{4 a}{\mathrm{PC}_{4} \mathrm{H}_{9}} \mathrm{SO}_{2} \mathrm{Ph}+\overbrace{\mathrm{DCE}, 90^{\circ} \mathrm{C}}^{\mathrm{AlCl}_{3}(1.5 \text { equiv) }} \underset{\mathrm{Th}}{\longrightarrow} \overbrace{\mathrm{SC}_{4} \mathrm{H}_{9}}
\end{aligned}
$$

Control experiments were conducted to explore the mechanism of this reaction. When the reaction of 1,1-diphenylethylene 9 was carried out under standard conditions, vinyl sulfone (10) was isolated in $86 \%$ isolated yield (Scheme 2 b). These results clearly indicate the formation of a benzenesulfonyl radical in the reaction system. The ${ }^{19} \mathrm{~F}$ NMR spectrum of the crude mixture from the reaction exhibited an additional signal at $-26 \mathrm{ppm}$, which was later determined to be from $\mathrm{IPrAuSCF}_{3}$ (8). This compound could be independently synthesized by the reaction of IPrAuCl and $\mathrm{AgSCF}_{3}$, which is sufficiently stable to be isolated by column chromatography (Scheme 2a). A stoichiometric reaction between IPrAuCl $2 \mathbf{a}$ and the radical scavenger (9) afforded vinyl sulfone (10) in $81 \%$ 
Table 3 Substrate scope of alkene thiosulfonylation reactions ${ }^{a}$

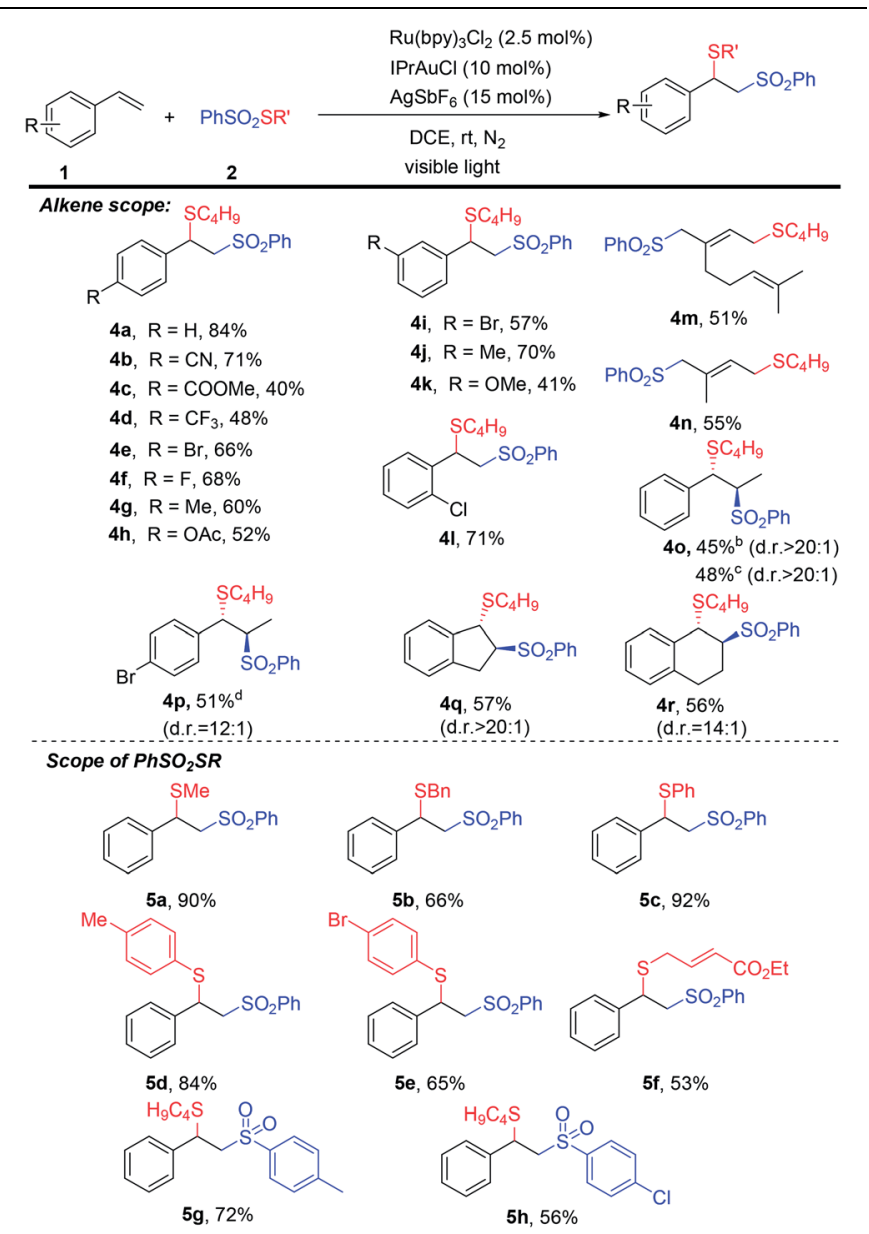

${ }^{a}$ Standard conditions were employed. Isolated yields were reported. Diastereoselectivities were determined by GC-mass. ${ }^{b}$ From $(E)$-alkene.

${ }^{c}$ From $(Z)$-alkene. ${ }^{d}$ From $(Z)$-alkene $:(E)$-alkene $=7: 3$.

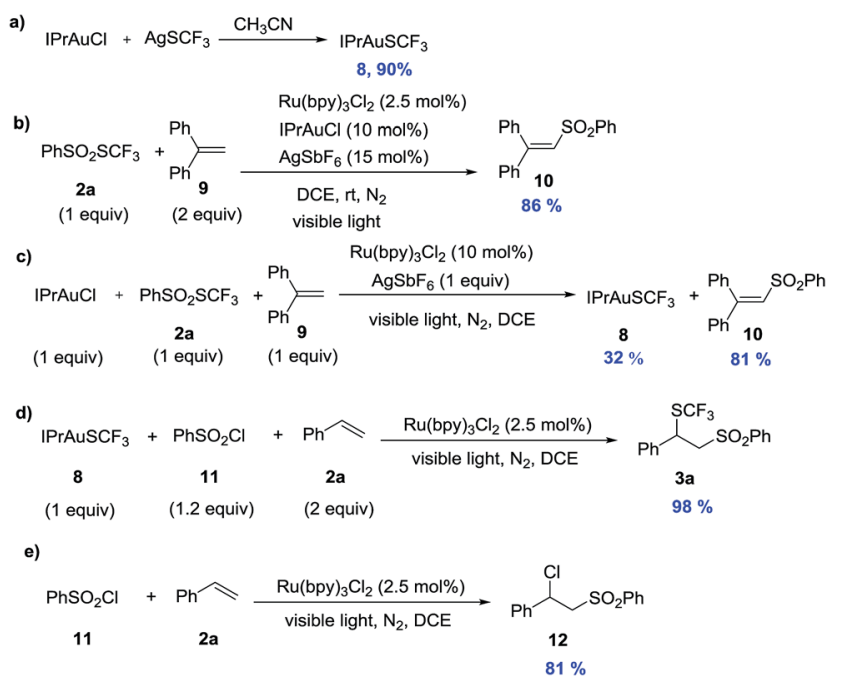

Scheme 2 Control experiments. isolated yield and 8 in $32 \%$ yield (Scheme $2 \mathrm{c}$ ). This benzenesulfonyl radical could also be generated by $\mathrm{PhSO}_{2} \mathrm{Cl}(\mathbf{1 1})$ in the presence of visible light, ${ }^{3 a}$ and the reaction between $\mathbf{8 , 1 1}$, and 2a afforded the target product (3a) in $98 \%$ yield (Scheme 2 d). In contrast, without this gold intermediate, the direct atom transfer radical addition adduct $\mathbf{1 2}$ was obtained in $81 \%$ yield (Scheme 2e). This experiment demonstrated that IPrAuSCF$_{3}$ is the possible reaction intermediate. ${ }^{17}$

Stern-Volmer fluorescence quenching experiments were performed to gain an insight into the photoredox catalytic cycle (for details, see the ESI (Fig. S1 and S2, ESI $\dagger$ )). The photoluminescence of $\mathrm{Ru}(\mathrm{bpy})_{3}{ }^{2+}$ was quenched by $\mathrm{IPrAuSbF}_{6}$ with a rate constant of $8.85 \times 10^{2} \mathrm{~L} \mathrm{~mol}^{-1}$. In contrast, $\mathrm{PhSO}_{2} \mathrm{SCF}_{3}$ $(-1.11 \mathrm{~V}$ vs. SCE $)$ and styrene cannot serve as emission quenchers. The cyclic voltammogram of $\mathrm{IPrAuSbF}_{6}$ contains a reversible reduction peak at $-0.11 \mathrm{~V}$ vs. SCE (Fig. S5, ESI $\dagger$ ), indicating that this cationic gold catalyst is easily reduced by the excited state of the photocatalyst $\mathrm{Ru}(\mathrm{bpy})_{3}{ }^{2+}\left(E_{1 / 2}^{\mathrm{III}}{ }^{*} \mathrm{II}=-0.81\right.$ $\mathrm{V} v$ s. SCE) ${ }^{10 b}$ To further characterize this electron transfer reaction, a flash-photolysis study was carried out (Fig. S3†). Upon laser excitation by $355 \mathrm{~nm}$ light, the ground state absorption at $\sim 450 \mathrm{~nm}$ was obviously bleached and a characteristic absorption band at $\sim 360 \mathrm{~nm}$ was detected. This is ascribed to the reductive state of bipyridine in $\mathrm{Ru}(\mathrm{bpy})_{3}\left(\mathrm{SbF}_{6}\right)_{2}$ (Fig. S4-a, ESI $\dagger$ ). ${ }^{18}$ When $\mathrm{PhSO}_{2} \mathrm{SCF}_{3}$ was introduced into a solution of $\mathrm{Ru}(\mathrm{bpy})_{3}\left(\mathrm{SbF}_{6}\right)_{2}$, the transient absorption spectra did not show any difference (Fig. S4-b, ESI†). The lifetime of the excited state of $\mathrm{Ru}(\mathrm{bpy})_{3}\left(\mathrm{SbF}_{6}\right)_{2}$ slightly decreased from 493 to $473 \mathrm{~ns}$, as observed from the kinetics probed at $450 \mathrm{~nm}$. However, when IPrAuSbF$_{6}$ was added to a solution of $\mathrm{Ru}(\mathrm{bpy})_{3}\left(\mathrm{SbF}_{6}\right)_{2}$, a new absorption peak appeared at $\sim 530 \mathrm{~nm}$. This is characteristic of gold nanoparticles. At the same time, the lifetime of the excited state of $\mathrm{Ru}(\mathrm{bpy})_{3}\left(\mathrm{SbF}_{6}\right)_{2}$ decreased from 493 to $394 \mathrm{~ns}$ (Fig. S4-c, ESI $\dagger$ ). All these results suggested that the electron transfer between $\mathrm{IPrAuSbF}_{6}$ and the excited ${ }^{3} \mathrm{MLCT}$ state of $\mathrm{Ru}(\mathrm{bpy})_{3}\left(\mathrm{SbF}_{6}\right)_{2}$ occurred, generating the active $\operatorname{IPrAu}(0)$ species that might aggregate to form gold nanoparticles. ${ }^{19}$ The reductive $\operatorname{IPrAu}(0)$ catalyst formed in situ is highly reactive ${ }^{20}$ and might react with $\mathrm{PhSO}_{2} \mathrm{SCF}_{3}$, providing $\mathrm{IPrAuSCF}_{3}(8)$ and a benzenesulfonyl radical.

On the basis of the abovementioned results and previous reports, ${ }^{12}$ a tentative proposed mechanism is shown in Scheme 3. Irradiation of $\mathrm{Ru}(\mathrm{bpy})_{3}{ }^{2+}$ generates a long-lived photoexcited state $\mathrm{Ru}(\mathrm{bpy})_{3}{ }^{2+*}$, which undergoes a single-electron transfer reaction with cationic IPrAu(I) to initiate the catalytic cycle and provide $\mathrm{Ru}(\mathrm{bpy})_{3}{ }^{3+}$ and the highly active $\operatorname{IPrAu}(0)$, which can reduce $\mathrm{PhSO}_{2} \mathrm{SCF}_{3}$ to form IPrAu(I)SCF$(8)$ and a benzenesulfonyl radical, which when added to styrene affords an alkyl radical. This radical is able to oxidize 8 to the $\mathrm{Au}(\mathrm{II})$ intermediate A, which is further oxidized to the $\mathrm{Au}(\mathrm{III})$ intermediate (B) by $\mathrm{Ru}(\mathrm{bpy})_{3}{ }^{3+}$, generating $\mathrm{Ru}(\mathrm{bpy})_{3}{ }^{2+}$ and thereby completing the photoredox catalytic cycle. Reductive elimination of the $\mathrm{Au}(\mathrm{III})$ intermediate $\mathbf{B}$ delivers the product and regenerates the $\mathrm{Au}(\mathrm{I})$ catalyst. This alkyl radical directly reacting with another equivalent of $\mathrm{PhSO}_{2} \mathrm{SCF}_{3}$ could also afford the target product via a radical chain mechanism. In our reaction, when the internal alkenes were employed as reaction substrates, excellent 


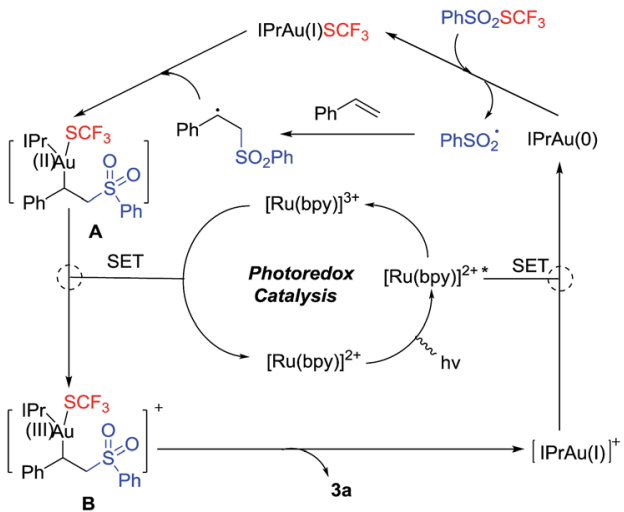

Scheme 3 Proposed mechanism.

diastereoselectivities were observed and both trans- and cisalkenes yielded the same diastereomer, which is not common in a pure radical reaction. The IPrAu(I) $\mathrm{SCF}_{3}$ (8) approached the in situ formed alkyl radical from the less sterically hindered side, which might contribute to the excellent diastereoselectivity of this reaction. The proposed dual gold photoredox catalytic cycle may be the major pathway although the radical chain reaction couldn't be excluded. This gold catalytic cycle from $\mathrm{Au}(0)$ to $\mathrm{Au}(\mathrm{III})$ is similar to that reported for nickel participating in photoredox catalytic cycles.

\section{Conclusions}

In summary, we have reported an intermolecular atom transfer thiosulfonylation reaction of alkenes. Both trifluoromethylthio group and other functionalized thio groups can be introduced into alkenes with excellent regioselectivity and diastereoselectivity. These reactions are promoted by a synergistic combination of gold catalysis and visible light photoredox catalysis. Detailed control experiments and reaction mechanism studies indicate that the gold catalyst experiences four different valencies from $\mathrm{Au}(0)$ to $\mathrm{Au}(\mathrm{III})$, which is unprecedented in previously reported Au-catalyzed transformations. This new dual gold and photocatalysis mode holds potential for applications to other important transformations.

\section{Acknowledgements}

We are grateful for the financial support received from the Natural Science Foundation of China and Shandong province (no. 21572118 \& JQ201505), the fundamental research and subject construction funds (No. 2014JC008, 104.205.2.5), and Zhong-Ying Tang scholar award of Shandong University. We thank Prof. Dr Di Sun who carried out the X-ray crystallographic analysis.

\section{Notes and references}

1 (a) R. I. McDonald, G. Liu and S. S. Stahl, Chem. Rev., 2011, 111, 2981; (b) K. H. Jensen and M. S. Sigman, Org. Biomol. Chem., 2008, 6, 4083.
2 (a) H. Zhu, P. Chen and G. Liu, J. Am. Chem. Soc., 2014, 136, 1766; (b) C. Chen, P. Chen and G. Liu, J. Am. Chem. Soc., 2015, 137, 15648; (c) R. Zhu and S. L. Buchwald, J. Am. Chem. Soc., 2015, 137, 8069; (d) Q. Lu, J. Zhang, F. Wei, Y. Qi, H. Wang, Z. Liu and A. Lei, Angew. Chem., Int. Ed., 2013, 52, 7156.

3 (a) C. Wallentin, J. D. Nguyen, P. Finkbeiner and C. R. J. Stephenson, J. Am. Chem. Soc., 2012, 134, 8875; (b) J. D. Nguyen, J. W. Tucker, M. D. Konieczynska and C. R. J. Stephenson, J. Am. Chem. Soc., 2011, 133, 4160; (c) R. Tomita, Y. Yasu, T. Koike and M. Akita, Angew. Chem., Int. Ed., 2014, 53, 7144; (d) R. Tomita, T. Koike and M. Akita, Angew. Chem., Int. Ed., 2015, 54, 12923; (e) Q. Qin, D. Ren and S. Yu, Org. Biomol. Chem., 2015, 13, 10295; $(f)$ D. H. R. Barton, M. A. Csiba and J. C. Jaszberenyi, Tetrahedron Lett., 1994, 35, 2869; $(g)$ D. B. Bagal, G. Kachkovskyi, M. Knorn, T. Rawner, B. M. Bhanage and O. Reiser, Angew. Chem., Int. Ed., 2015, 54, 6999; (h) T. Courant and G. Masson, J. Org. Chem., 2016, 81, 6945.

4 C. Hansch, A. Leo, S. H. Unger, K. H. Kim, D. Nikaitani and E. J. Lien, J. Med. Chem., 1973, 16, 1207.

5 (a) J. F. Giudicelli, C. Richer and A. Berdeaux, Br. J. Clin. Pharmacol., 1976, 3, 113; (b) A. Harder and A. Haberkorn, Parasitol. Res., 1989, 76, 8.

6 (a) X. Shao, X. Wang, T. Yang, L. Lu and Q. Shen, Angew. Chem., Int. Ed., 2013, 52, 3457; (b) G. Teverovskiy, D. S. Surry and S. L. Buchwald, Angew. Chem., Int. Ed., 2011, 50, 7312; (c) C. Zhang and D. A. Vicic, J. Am. Chem. Soc., 2012, 134, 183; (d) A. Ferry, T. Billard, B. R. Langlois and E. Bacque, Angew. Chem., Int. Ed., 2009, 48, 8551; (e) G. Danoun, B. Bayarmagnai, M. F. Gruenberg and L. J. Goossen, Chem. Sci., 2014, 5, 1312; (f) Q. Xiao, Q. He, J. Li and J. Wang, Org. Lett., 2015, 17, 6090; (g) J. Luo, Z. Zhu, Y. Liu and X. Zhao, Org. Lett., 2015, 17, 3620.

7 (a) L. Zhu, G. Wang, Q. Guo, Z. Xu, D. Zhang and R. Wang, Org. Lett., 2014, 16, 5390; (b) F. Yin and X. Wang, Org. Lett., 2014, 16, 1128; (c) K. Zhang, J. Liu and F. Qing, Chem. Commun., 2014, 50, 14157; (d) M. Hu, J. Rong, W. Miao, C. Ni, Y. Han and J. Hu, Org. Lett., 2014, 16, 2030; (e) Y. Zeng and J. Hu, Org. Lett., 2016, 18, 856; (f) R. Honeker, R. A. Garza-Sanchez, M. N. Hopkinson and F. Glorius, Chem.-Eur. J., 2016, 22, 4395.

8 F. Zhao, J. Wang, X. Ding, S. Shu and H. Liu, Chin. J. Org. Chem., 2016, 36, 490.

9 C. Najera and M. Yus, Tetrahedron, 1999, 55, 10547.

10 For reviews of visible-light photoredox catalysis, see: (a) J. Xuan, Z. Zhang and W. Xiao, Angew. Chem., Int. Ed., 2015, 54, 15632; (b) C. K. Prier, D. A. Rankic and D. W. C. MacMillan, Chem. Rev., 2013, 113, 5322; (c) J. Xuan and W. Xiao, Angew. Chem., Int. Ed., 2012, 51, 6828; (d) J. M. R. Narayanam and C. R. J. Stephenson, Chem. Soc. Rev., 2011, 40, 102; (e) T. P. Yoon, M. A. Ischay and J. Du, Nat. Chem., 2010, 2, 527; $(f)$ T. Chatterjee, N. Iqbal, Y. You and E. J. Cho, Acc. Chem. Res., 2016, 49, 2284.

11 For review, see: (a) K. L. Skubi, T. R. Blum and T. P. Yoon, Chem. Rev., 2016, 116, 10035; For combination of photoredox with palladium catalysis, see: (b) D. Kalyani, 
K. B. McMurtrey, S. R. Neufeldt and M. S. Sanford, J. Am. Chem. Soc., 2011, 133, 18566; (c) S. R. Neufeldt and M. S. Sanford, Adv. Synth. Catal., 2012, 354, 3517; (d) J. Zoller, D. C. Fabry, M. A. Ronge and M. Rueping, Angew. Chem., Int. Ed., 2014, 53, 13264; (e) J. Xuan, T. Zeng, Z. Feng, Q. Deng, J. Chen, L. Lu, W. Xiao and H. Alper, Angew. Chem., Int. Ed., 2015, 54, 1625; With nickel catalysis, see: (f) Z. Zuo, D. T. Ahneman, L. Chu, J. A. Terrett, A. G. Doyle and D. W. C. MacMillan, Science, 2014, 345, 437; $(g)$ J. C. Tellis, D. N. Primer and G. A. Molander, Science, 2014, 345, 433; $(h)$ J. A. Terrett, J. D. Cuthbertson, V. W. Shurtleff and D. W. C. MacMillan, Nature, 2015, 524, 330; (i) Z. Zuo, H. Cong, W. Li, J. Choi, G. C. Fu and D. W. C. MacMillan, J. Am. Chem. Soc., 2016, 138, 1832; With copper catalysis, see: (j) Y. Ye and M. S. Sanford, J. Am. Chem. Soc., 2012, 134, 9034.

12 For combination of photoredox with gold catalysis, see: $(a)$ M. N. Hopkinson, A. Tlahuext-Aca and F. Glorius, Acc. Chem. Res., 2016, 49, 2261; (b) B. Sahoo, M. N. Hopkinson and F. Glorius, J. Am. Chem. Soc., 2013, 135, 5505; (c) M. N. Hopkinson, B. Sahoo and F. Glorius, Adv. Synth. Catal., 2014, 356, 2794; (d) X. Shu, M. Zhang, Y. He, H. Frei and F. D. Toste, J. Am. Chem. Soc., 2014, 136, 5844; (e) Y. He, H. Wu and F. D. Toste, Chem. Sci., 2015, 6, 1194; (f) S. Kim, J. Rojas-Martin and F. D. Toste, Chem. Sci., 2016, 7, 85; $(g)$ J. Um, H. Yun and S. Shin, Org. Lett., 2016, 18, 484; (h) L. Huang, M. Rudolph, F. Rominger and A. S. K. Hashmi, Angew. Chem., Int. Ed., 2016, 55, 4808; (i) T. Cornilleau, P. Hermange and E. Fouquet, Chem. Commun., 2016, 52, 10040; (j) V. Gauchot and A.-L. Lee, Chem. Commun., 2016, 52, 10163; ( $k$ ) A. Tlahuext-Aca, M. N. Hopkinson, C. G. Daniliuc and F. Glorius, Chem.Eur. J., 2016, 22, 11587; (l) A. Tlahuext-Aca, M. N. Hopkinson, B. Sahoo and F. Glorius, Chem. Sci., 2016, 7, 89; ( $m$ ) A. Tlahuext-Aca, M. N. Hopkinson, R. A. Garza-Sanchez and F. Glorius, Chem.-Eur. J., 2016, 22,
5909; (n) Q. Zhang, Z. Zhang, Y. Fu and H. Yu, ACS Catal., 2016, 6, 798; (o) D. V. Patil, H. Yun and S. Shin, Adv. Synth. Catal., 2015, 357, 2622; (p) B. Alcaide, P. Almendros, E. Busto and A. Luna, Adv. Synth. Catal., 2016, 358, 1526; (q) L. Huang, F. Rominger, M. Rudolpha and A. S. K. Hashmi, Chem. Commun., 2016, 52, 6435.

13 Gold(I) as photocatalyst, see: (a) G. Revol, T. MaCallum, M. Morin, F. Gagosz and L. Barriault, Angew. Chem., Int. Ed., 2013, 52, 13342; (b) J. Xie, S. Shi, T. Zhang, N. Mehrkens, M. Rudolph and A. S. K. Hashmi, Angew. Chem., Int. Ed., 2015, 54, 6046.

14 (a) G. Zhang, L. Cui, Y. Wang and L. Zhang, J. Am. Chem. Soc., 2010, 132, 1474; (b) W. E. Brenzovich, D. Benitez, A. D. Lackner, H. P. Shunatona, E. Tkatchouk, W. A. Goddard III and F. D. Toste, Angew. Chem., Int. Ed., 2010, 49, 5519; (c) T. de Haro and C. Nevado, Angew. Chem., Int. Ed., 2011, 50, 906; (d) H. Peng, Y. Xi, N. Ronaghi, B. Dong, N. G. Akhmedov and X. Shi, J. Am. Chem. Soc., 2014, 136, 13174.

15 (a) E. A. Ilardi, E. Vitaku and J. T. Njardarson, J. Med. Chem., 2014, 57, 2832; (b) M. Feng, B. Tang, S. H. Liang and X. Jiang, Curr. Top. Med. Chem., 2016, 16, 1200.

16 (a) H. Liu and X. Jiang, Chem.-Asian J., 2013, 8, 2546; (b) Z. Qiao and X. Jiang, Org. Lett., 2016, 18, 1550; (c) W. Wang, X. Peng, F. Wei, C. Tung and Z. Xu, Angew. Chem., Int. Ed., 2016, 55, 649.

17 A. S. K. Hashmi, Angew. Chem., Int. Ed., 2010, 49, 5232.

18 X. Gao, Q. Meng, J. Li, J. Zhong, T. Lei, X. Li, C. Tung and L. Wu, ACS Catal., 2015, 5, 2391.

19 For N-heterocyclic carbene modified gold surfaces, see: A. V. Zhukhovitskiy, M. G. Mavros, T. V. Voorhis and J. A. Johnson, J. Am. Chem. Soc., 2013, 135, 7418.

20 Gold nanoparticle could reduce thiol to form $\mathrm{Au}-\mathrm{S}$ bond and release $\mathrm{H}_{2}$, see: J. E. Matthiesen, D. Jose, C. M. Sorensen and K. J. Klabunde, J. Am. Chem. Soc., 2012, 134, 9376. 